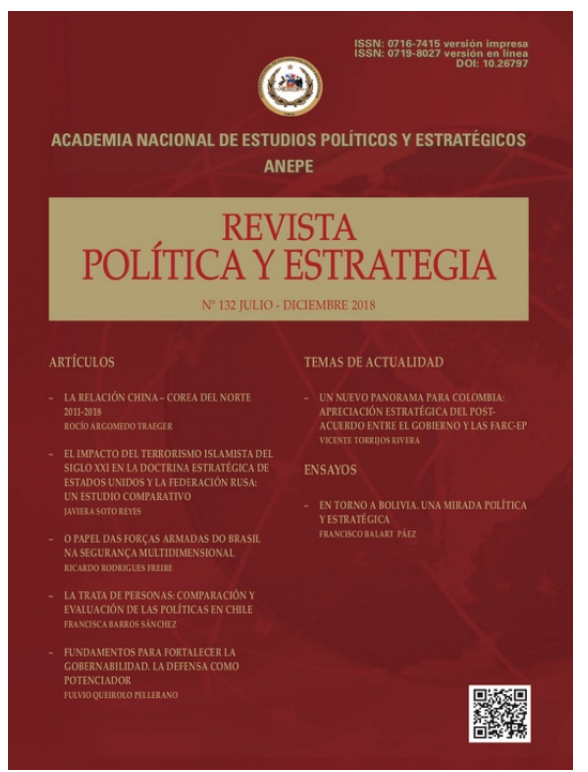

Para citar este artículo / To cite this article: ARGOMEDO Traeger, Rocío: "La relación China - Corea del Norte 2011-2018."

Revista Política y Estrategia No 132, pp. 21-46

DOI: https://doi.org/10.26797/rpye.v0i132.235

\section{Editada por: Academia Nacional de Estudios Políticos y Estratégicos (ANEPE) Chile.}

Lugar de edición: Santiago, Chile

Dirección web:

http://www.politicayestrategia.cl

ISSN versión digital: $\quad$ 0719-8027

ISSN versión Impresa: 0716-7415
DOI: https://doi.org/10.26797/rpye.v0i132

Si desea publicar en Política y Estrategia, puede consultar en este enlace las Normas para los autores:

To publish in the journal go to this link:

http://politicayestrategia.cl/index.php/rpye/about/submissions\#authorGuidelines

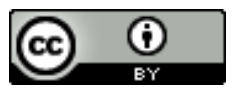

La Revista Política y Estrategia está distribuida bajo una Licencia Creative Commons Atribución 4.0 Internacional. 


\title{
LA RELACIÓN CHINA - COREA DEL NORTE 2011-2018
}

\author{
ROCÍO ARGOMEDO TRAEGER*
}

\begin{abstract}
RESUMEN
La relación de China con Corea del Norte se ha debilitado desde 2011, con la llegada de Kim Jong Un, y también se ha tensionado bajo el Gobierno de Xi Jin Ping. No obstante, el cumplimiento parcial que ha mantenido China respecto al régimen de sanciones de Naciones Unidas hacia Corea del Norte no es determinante en la relación de compañerismo entre ambos países. Estados Unidos, la creación de identidad y la construcción de un discurso de fraternidad, han sido variables intervinientes en una relación de co-dependencia gradual entre ambos países. Esto dará una panorámica para entender qué lineamientos serán de utilidad en la estrategia de inserción de Chile en el escenario asiático, como actor bisagra cuya columna vertebral es el Pacífico, y así afianzarse como puente hacia Asia.
\end{abstract}

Palabras clave: China; Corea del Norte; Estados Unidos; desnuclearización; Pacífico.

\section{THE RELATIONSHIP CHINA - NORTH KOREA 2011-2018}

\begin{abstract}
Kim Jong Un's arrival on power and Xi Jin Ping's government have weakened China's relationship with North Korea since 2011. However, China's partial compliance with the United Nations sanctions regime towards North Korea is not decisive in the fellowship between the two countries. The United States, the creation of identity and the construction of a fraternity discourse, have been intervening variables in a liaison of gradual co-dependence between both countries. The study of these elements can give us an overview in order to understand which guidelines will be useful in Chile's
\end{abstract}

* Analista en Políticas y Asuntos Internacionales, Licenciada en Seguridad y Defensa y Magíster en Estudios Internacionales. Actualmente pertenece al Servicio Exterior del Ministerio de Relaciones Exteriores de Chile. rocio.argomedo@gmail.com ORCID: http://orcid.org/0000-0002-5271-7316

El presente escrito representa única y exclusivamente el parecer y análisis de la autora, y no la posición del Ministerio de Relaciones Exteriores de Chile

$\infty \quad$ Fecha de recepción: 080818 - Fecha de aceptación: 311018. 
insertion strategy into the Asian scenario, as a hinge actor whose backbone is the Pacific and thus consolidate itself as a bridge to Asia.

Key words: China; North Korea; United States; denuclearization; Pacific.

\section{A RELAÇÃO CHINA - CORÉIA DO NORTE 2011-2018}

\section{RESUMO}

A relação da China com a Coréia do Norte foi enfraquecida desde 2011, com a chegada de Kim Jong un, e também foi forçado o governo de Xi Jin Ping. No entanto, a conformidade parcial da China com o regime de sanções das Nações Unidas para a Coreia do Norte não é decisiva na relação de comunhão entre os dois países. Os Estados Unidos, a criação de identidade e a construção de um discurso de fraternidade, têm sido variáveis que intervem em uma relação de codependência gradual entre os dois países. Isto dará uma visão panorâmica do que as orientações serão úteis na estratégia de inserção do Chile no cenário asiático, como um ator dobradiça cuja espinha dorsal é o Pacífico, e, assim, consolidar-se como uma ponte para a Ásia.

Palavras-chave: China; Coréia do Norte; Estados Unidos; Desnuclearização; Pacífico.

\section{INTRODUCCIÓN}

La República Popular Democrática de Corea (RPDC) ha provocado tensión mundial en relación a su capacidad nuclear y la incipiente amenaza que altera la paz a nivel global. China ha sido históricamente un aliado importante de este país, y a su vez se ha ido posicionando como una potencia en ascenso. Este escenario impactará en el rol y liderazgo que la potencia asiática ejercerá respecto al proceso de desnuclearización de la península coreana en el marco de no perder influencia en el sistema internacional.

La relación China - Corea del Norte se ha debilitado desde 2011, con la llegada de Kim Jong Un, y también se ha tensionado bajo el Gobierno de Xi Jin Ping. No obstante, el cumplimiento parcial que ha mantenido el gigante asiático respecto al régimen de sanciones de Naciones Unidas no es determinante en la reciprocidad y compañerismo entre ambos países.

Por un lado, para Corea del Norte, China es su principal socio comercial y pilar importante de su política exterior, por lo que no puede costear cortar re- 
laciones con ella, especialmente al considerar el aislacionismo que ha padecido Corea del Norte.

Por otra parte, si bien el gigante oriental busca la desnuclearización de la península, la estabilidad se convierte en un bien prioritario. Por esto, China ha concedido a la sociedad internacional el apoyo para establecer sanciones a un aliado y así demostrar control sobre este, especialmente como medida de retaliación a raíz del comportamiento impredecible que Corea del Norte ha manifestado el último tiempo.

El estudio de la relación Corea del Norte - China, considerada esta última como potencia en ascenso (económico, militar y cultural), permitirá identificar elementos que reflejen la importancia de dicho vínculo con la integración de Chile en la región asiática.

El objetivo principal de esta investigación es identificar la dinámica de la conexión de ambos actores asiáticos, más allá del vínculo estratégico que busca limitar la influencia de otros actores internacionales en la región. Para ello es necesario Identificar elementos que reflejen la importancia de dicha relación con la participación de Chile en la región asiática.

Para lograr lo anterior, inicialmente se presentará un breve marco teórico que describirá el lente que orientará la investigación. Posterior a ello, el estudio comenzará con las características principales de la Política Exterior de China, Corea del Norte y Chile, para luego desarrollar el análisis que permita responder a las preguntas de la investigación al identificar los patrones de la relación China-Corea del Norte y la relación de Chile con los otros dos países en estudio. Finalmente, las conclusiones demostrarán la solución al problema planteado y la forma en que se cumplen los objetivos fijados para este escrito.

\section{Introducción teórica}

Desde la disciplina de las Relaciones Internacionales, el estudio de dos países asiáticos como China y Corea del Norte bajo un prisma constructivista logra reparar en la escasa investigación de una potencia bajo parámetros más allá de lo cuantitativo-comercial, y cuya heterogeneidad cultural no siempre es contemplada por Occidente. Por otra parte, investigar la complejidad de ambos países, y en particular su relación, es clave para entender cómo se articula el sistema de alianzas en una región de importancia estratégica para Chile como puente hacia el Pacífico.

Para el constructivismo la realidad es socialmente establecida y mutuamente constitutiva, es por ello que la variable central de su estudio es la identidad y cómo esta se va articulando. Una de las orientaciones principales que problematiza esta teoría va de la mano con lo señalado por Robert Cox: "Theory 
is always for someone and for some purpose."1, donde la construcción de saberes va definiendo las realidades y cómo esto no puede despegarse del sentido de pertenencia e identidad que se va cimentando alrededor de dichos constructos normativos.

Tal y como lo describe Barbé ${ }^{2}$, el constructivismo entiende por actores internacionales a los Estados, entidades con identidades endógenas y relativamente estables. Dicha condición lo transforma en un role player, cuyo rol viene marcado por las normas/instituciones en las que los participantes están socializados y que son socialmente construidas.

Los actores no representan simplemente puntos de vista e intereses particulares, sino también "descubren" sus aspiraciones a través de un proceso social donde la argumentación y persuasión cobran una especial relevancia a través de la intersubjetividad del conocimiento y de los hechos como acuerdos colectivos que se enmarcan en un contexto de consenso entre los agentes involucrados. Así, tal y como lo indica Emanuel Adler ${ }^{3}$, tanto los actores como su comportamiento están habilitados y legitimados por el discurso social más amplio en el que están inmersos, al construirse cognitivamente a nivel colectivo indicaciones de cómo deberían usar sus capacidades materiales y su poder.

Por otra parte, es necesario entender el presupuesto de que la emergencia de potencias económicas que logran contrastar el poderío norteamericano hace entrever que la dinámica que adoptará China con EE.UU. puede ser concebida como soft balancing. Este, entendido como "acciones que no desafían directamente su preponderancia militar, sino que utilizan herramientas no militares para retrasar, frustrar y socavar las políticas militares estadounidenses unilaterales agresivas"4.

Esto puede complementarse con lo que Alka Acharya ${ }^{5}$ entiende por Relaciones Internacionales No-hegemónicas -NHIOT en sus siglas en inglés- afirmando que estas son "un patrón relativamente estable de interacciones dentro de un grupo de Estados sin la hegemonía individual o colectiva de grandes poderes"6. Al igual que el constructivismo, esta corriente teórica permite explicar cómo la estructura del sistema internacional es tanto ideacional como material. No obstante, la RPDC ha ido estableciendo una dinámica más directa de contrapeso en la es-

COX, R. Social Forces, States and World Orders: Beyond International Relations Theory, 1981. p. 128.

BARBÉ, Esther. Relaciones Internacionales. Editorial Tecnos (Grupo Anaya S.A.), Madrid. 2007.

ADLER, Emanuel. Seizing the Middle Ground: Constructivism in World Politics. European Journal of International Relations. 1997.

4 PAPE, Robert. "Soft Balancing against the United States". Triangle Institute on Security Studies at Duke University. 2003. p. 10.

5 ACHARYA, Alka. India-China Relations: Towards a Shared Vision. Economic and Policital Weekly. VOI. 43. $N^{\circ}$. 4. 2008

$6 \quad$ lbíd. p. 1. 
tructura global a partir de su política de "lo militar es prioritario" en función de la defensa de sus intereses nacionales. Es por ello que tanto China como la República Popular Democrática de Corea irán representando un binomio que entrelaza el poder duro con el blando, solo que, de forma más compartimentada, y donde China cumple el rol de contención para la RPDC, manifestada como el garrote.

\section{CARACTERÍSTICAS PRINCIPALES DE LA POLÍTICA EXTERIOR DE CHINA, COREA DEL NORTE Y CHILE}

\section{China}

Uno de sus principales objetivos es impulsar positivamente el establecimiento de un nuevo orden político y económico internacional que sea justo y razonable, adhiriéndose a los cinco principios de coexistencia pacífica: respeto mutuo a la soberanía y la integridad territorial, no agresión recíproca, ni intervención en los asuntos internos del uno al otro, igualdad y beneficio mutuo.

Junto a esto, "reforzar la unidad y la cooperación con los países en vías de desarrollo constituye una base de apoyo fundamental de la política exterior de China. La potencia asiática y los países en vías de desarrollo han experimentado los mismos sufrimientos históricos y enfrentan la meta común de defender la independencia nacional y conseguir el desarrollo económico. La base de sus colaboraciones es sólida y su porvenir, brillante"7. Mayoritariamente, en los objetivos se plasma la intencionalidad de crear una imagen pacifista y fraternal, materializado en su política de colaboración a países en desarrollo.

Con la identificación de una comunidad de "desprotegidos" en el sistema internacional, respalda las críticas que puedan despertar en términos de Derechos Humanos a través de las convenciones firmadas, y su participación activa en el Consejo de Seguridad de Naciones Unidas lo enmarca en la noción de país responsable y líder a nivel global, no solo continental.

Asimismo, los principios confucionistas de perfeccionamiento individual, la pertenencia a la colectividad, la armonía social y el buen gobierno han estado latentes en la dinámica de política tanto doméstica como exterior china, conviviendo a nivel sistémico. Aquel marco oriental ha estado presente desde la antigüedad, como cultura milenaria, lo cual también puede verse reflejado en otros territorios y culturas de la región, como la norcoreana.

\section{Corea del Norte}

La península norcoreana ha basado los lineamientos de su política exterior bajo la construcción de un sentimiento colectivo de resguardo, en defensa al ré-

7 FMPRC Política exterior de paz bajo el principio de independencia y autodecisión de China. Ministerio de Relaciones Exteriores de la República Popular China. [En línea] 24 de agosto 2003. 
gimen. A partir de esto, desde el mandato de Kim Jong II la RPDC ha cimentado su política disuasiva a través del desarrollo de armas nucleares.

Desde 1926, en el contexto de ocupación japonesa, Corea del Norte comenzó a desarrollar la política de Songun, la cual prioriza los asuntos militares de defensa del país y de la revolución socialista para luchar contra el imperialismo. La idea de priorización militar es complementada con el Juche, lineamiento con raíces budistas que promueve el principio de independencia y autosuficiencia en el marco de defender la construcción del socialismo.

En paralelo, la administración norcoreana fue desarrollando un culto al personalismo, construyendo un imaginario nacional basado en los "padres" protectores, que se materializaron en Kim il Sung, como el Presidente Eterno de la República, y Kim Jong II titulado como "Líder Supremo".

Este culto al personalismo se fue articulando con imaginarios colectivos de la antigüedad, basándose en los principios y directrices que de alguna manera habían permeado en el sistema socio cultural de la península norcoreana. Así, "las élites de Corea del Norte, especialmente Kim II Sung y Kim Jong II, reinventaron y manipularon diversas formas de confucianismo porque querían legitimar su dominación"8.

Asimismo, no solo Confucio, sino que Mencio también forjaron las bases de la construcción de legitimidad de la política jerárquica norcoreana. "El neoconfucianismo fue el sistema de valores dominante de la dinastía Choson (13921910). Combina la ética social de los filósofos chinos clásicos Confucio (551-479 a.C.) y Mencio (372 a 289 a.C.). Una de las ideas clave del neoconfucianismo fue que las instituciones y las prácticas de una comunidad humana ordenada expresan los principios que rigen el cosmos. Por lo tanto, el neoconfucianismo define las relaciones sociales no en términos de satisfacción de los individuos involucrados, sino en términos de la integración armoniosa de los individuos en un todo colectivo que presenta la armonía del orden natural. La doctrina enfatizó la jerarquía en las relaciones humanas".

\section{Chile}

Como país de renta media ha intentado insertarse en el contexto internacional a través de su contribución al fortalecimiento del multilateralismo y su apertura unilateral al comercio internacional. De esta manera, ayudado de su posición geoestratégica, ha intentado sentar camino como país puente al Asia-Pacífico.

Autores como Keohane han criticado la tendencia que se ha gestado en los estudios de relaciones internacionales al rendir en función de una sola poten-

8 LEVI, Nicolas. The Importance of Confucian values to Kim Jong Il's System: A comparison with Kim II Sung's Syste. 2012. Poland Asia Research Center. p. 3.

$9 \quad$ lbíd. p. 5. 
cia, los Estados Unidos, demostrando monotonía. Por ello, si prestamos atención a un escenario no occidental dentro del esquema mundial de poder, podremos contemplar cómo la interdependencia compleja se ve reflejada en la lógica de las cadenas globales de producción. En el caso de un país como Chile, con una matriz exportadora que necesita ser diversificada, su economía seguirá estando anclada a países de gran demanda cuprífera, como el gigante asiático.

Así como el autor de 'la interdependencia compleja' cita a Goldman para señalar que: "las relaciones internacionales no deberían concebirse como una 'competición oligopolística' entre distintos conglomerados liderados por los Estados Unidos que han de ser aceptados o rechazados in toto"'10, lo mismo aplica cuando la aparente multipolaridad del sistema internacional se estanca en el pensamiento de que China es el único referente comercial al haber dispersado la hegemonía concentrada en EE.UU.

Frente a lo anterior, Chile como actor bisagra a nivel político siempre ha sido capaz de posicionarse en un punto intermedio entre China y EE.UU., sus principales socios comerciales. De esta manera, si se agudizaran los factores de tensión en la región asiática, el país latinoamericano podría hacer uso de alianzas a nivel intra regional para compensar las eventuales pérdidas y obstáculos que se presentarían en caso de una escalada de conflicto en la península coreana.

Por otra parte, la necesidad de diversificar las inversiones asiáticas en nuestro país y la concentración en China como principal mercado al que van destinadas nuestras exportaciones nos obliga a mantenernos activos en el desafío de diversificar la atracción de inversiones.

Corea del Sur es nuestro quinto socio comercial, luego de China, Estados Unidos, Brasil y Japón, ocupando un lugar importante en nuestra articulación como país puente al Asia Pacífico. Por esto, la modernización de nuestro TLC (2004) con Corea del Sur es un paso estratégico, que refleja que la idea puente de Chile hacia la región asiática es multidireccional y que intenta caminar hacia la adaptación del mercado, con la incorporación de nuevos temas, como lo es medio ambiente, género, entre otros, y proyectar nuevas áreas de cooperación.

Estrategias como la actualización de Tratados de Libre Comercio o Acuerdos de Asociación han sido la herramienta clave de Chile para poder enfrentar eventuales vaivenes del escenario internacional. Ejemplo de ello es la modernización del Acuerdo de Asociación Estratégica que sostiene con la UE (2002), cuyas negociaciones están en curso, y el eventual acuerdo que se realice con Reino Unido en un contexto post Brexit.

10 KEOHANE, Robert. Relaciones Internacionales: Lo viejo y lo Nuevo. Nuevo Manual de Ciencia Política Editorial Istmo, España. 2001. p. 685. 
No obstante, la matriz productiva chilena requiere mayor diversificación, independiente de los factores externos que puedan hacer del país del cobre un eslabón débil de los efectos negativos de la interdependencia compleja.

Desde una arista de índole más político, Chile se ha posicionado como un país promotor de la paz y la seguridad internacional, y para ello se ha dedicado a colaborar a nivel regional a esto. Un ejemplo de ello ha sido su participación en Operaciones de Paz de Naciones Unidas, como en su minuto fue la Misión de Estabilización de las Naciones Unidas en Haití (MINUSTAH), así como su papel de país bisagra y articulador de diálogo en el Proceso de Paz en Colombia.

Chile ha creado un discurso conciliador a lo largo de su política exterior, lo cual lo ha hecho un país confiable y pragmático. Ejemplo de ello ha sido su relación con países que, si bien no han compartido visiones político-ideológicas en común, las relaciones han permanecido cercanas. El caso más emblemático de esto ha sido la relación que ha sostenido con la República Popular China, incluso en el escenario en que ambos Estados estaban siendo administrados por ideologías opuestas en contexto de Guerra Fría, pero en donde aún se conservaban los vínculos bilaterales y las relaciones diplomáticas ${ }^{11}$.

\section{PLAN DE DESARROLLO NUCLEAR NORCOREANO}

Como mencionamos anteriormente, la República Popular Democrática de Corea ha llevado a cabo un ambicioso plan de desarrollo de armas nucleares, el que se acentuó con el término de la Guerra Fría. En ese contexto, el país asiático ya no contaba con el apoyo de sus aliados tradicionales, particularmente la entonces Unión Soviética. Ante la aislación internacional y con el objetivo de resguardar su soberanía, el gobierno norcoreano comenzó su estrategia disuasiva a partir del desarrollo de armamento nuclear, lo que significó el retiro del país como Estado miembro del Tratado de No Proliferación Nuclear en 2003.

En enero de 2016, la RPDC notificó una prueba de bomba de hidrógeno, ensayo detectado por un sismo artificial en las cercanías de las instalaciones nucleares norcoreanas. A diferencia de ocasiones anteriores, la prueba no fue notificada a China ni a Estados Unidos, por lo que el Consejo de Seguridad de Naciones Unidas se reunió para abordar el tema. Los miembros del Consejo condenaron categóricamente el ensayo calificándolo de una amenaza a la paz y seguridad internacional.

A pesar de la condena casi unánime de la comunidad internacional, el 7 de febrero de 2016, Corea del Norte realizó una prueba de lanzamiento de un misil

COLACRAI, Miryam y LORENZINI, María Elena. La política exterior de Chile: ¿excepcionalidad o continuidad? Una lectura combinada de "fuerzas profundas" y tendencias. CONfines relacion. internaci. ciencia política [online]. 2005, vol.1, n.2, pp. 45-63. ISSN 1870-3569. 
de largo alcance, que tendría la posibilidad de transportar una cabeza nuclear. Desde la confirmación de este hecho no cesaron las reacciones de organismos multilaterales y de diversos Estados. Esta se convertiría en la quinta prueba nuclear realizada por el gobierno de Kim Jong Un, tras haber ejecutado otras en 2006, 2009, 2013 y en enero de 2016.

Tanto Japón, como Corea del Sur y Estados Unidos han acordado responder de manera unida frente al comportamiento transgresor de Corea del Norte. Por su parte China, en su calidad de líder regional asiático, se ha visto mermada en su actuar por el rol activo de Estados Unidos en Asia. Frente a esto, Beijing instó a Corea del Norte a abstenerse de medidas que puedan escalar las tensiones tanto regionales como internacionales.

Frente al accionar pasivo de China en relación a las insistencias del gobierno norcoreano por manifestarse como Estado nuclear, a comienzos de 2016 Corea del Sur y Estados Unidos iniciaron conversaciones para la instalación del sistema antimisiles Terminal High Altitude Area Defense (THAAD), el cual tiene por objeto rastrear movimientos logísticos de China en su territorio y otros territorios del Noreste de Asia.

Para marzo de 2016 el Consejo de Seguridad de Naciones Unidas aprobó la Resolución 2270 que endurece notoriamente las sanciones que se ejercían contra la RPDC. Estas medidas incluyen la inspección de toda carga dirigida o proveniente de la península norcoreana, la extensión del embargo de armamento a las armas pequeñas y ligeras, cierre de cuentas corrientes y congelamiento de activos, prohibición de venta de combustible para aviones o cohetes y la prohibición de venta, por parte de Corea del Norte, de sus reservas de carbón y hierro.

A fines de agosto e inicios de septiembre de 2016, el país gobernado por Kim Jong Un nuevamente hizo pruebas de lanzamiento de cuatro misiles balísticos, y el primero de ellos correspondía al lanzamiento desde un submarino dirigido hacia la costa oriental. Esto generó un punto de inflexión dentro de la capacidad disuasiva de Corea del Norte, especialmente si se considera que la proyección del misil fue tal que pudo volar más de $500 \mathrm{~km}$ superando el umbral que antes mantenía en sus anteriores ensayos. Ello implicó una reacción del Consejo de Seguridad, a través de una declaración de prensa, en que condenó enérgicamente el lanzamiento de estos misiles.

El 9 de septiembre de 2017, la Corea comunista realizó su quinta prueba nuclear, poniendo en tela de juicio la efectividad que pudo haber tenido la Resolución 2270 del Consejo de Seguridad. Dicha resolución ha sido considerada una de las más significativas contra el régimen de la RPDC, ya que buscó la desestabilización económica de Corea del Norte y generar una percepción de falta de apoyo. Al ser avalada por China, esto generó una merma simbólica en la solidez norcoreana. 
Aquel ensayo al haber sido dirigido al mar del Japón, generó mayor reacción por parte de la comunidad internacional, ya que además de haber significado una amenaza desestabilizadora, involucraba un mayor alcance de su capacidad de provocar a otros actores de la región. Si bien la seguridad del Noreste de Asia se veía en peligro, esto implicó una llamada para acelerar una respuesta por parte de la comunidad internacional. Con ello se forjó la reacción proactiva de dos binomios; por un lado, Estados Unidos y Corea del Sur a través de la instalación de un Sistema Anti-misiles, y por otro el malestar del binomio del soft balancing: China y Rusia, propio de la resistencia a la hegemonía como tendencia natural.

El último ensayo nuclear norcoreano tuvo lugar el 3 de septiembre de 2017, el cual, según la RPDC, consistió en la detonación subterránea de una bomba de hidrógeno, la que podría ser incorporada a un misil balístico intercontinental. La prueba motivó una nueva reunión de emergencia del Consejo de Seguridad de Naciones Unidas y desató fuertes críticas por parte de Estados Unidos, Corea del Sur, Japón, inclusive de Rusia y China.

A fines de noviembre de 2017, la RPDC lanzó nuevamente un misil balístico intercontinental, el cual cayó sobre la zona económica exclusiva de Japón. Con esta maniobra, el gobierno norcoreano declaró que el país ya había completado la tarea de convertirse en un Estado nuclear. Corea del Sur estableció un discurso de aislamiento de Corea del Norte, refrendándolo como actor auto-marginado del sistema internacional. Fue así como nuevamente se dio la aprobación de una nueva resolución del Consejo de Seguridad de Naciones Unidas el 22 de diciembre de 2017.

De esta manera, Corea del Norte calificó las nuevas sanciones como una consolidación del bloqueo económico al país, convocando principios universales del derecho internacional al catalogarlo como un "acto de guerra" que infringe la soberanía del país, violando la paz y estabilidad en la península coreana. Junto a esto, la RPDC reafirmó que los usos de armas nucleares cumplían la función disuasiva de auto defensa que no contradice ninguna ley internacional. En esto, Corea del Norte argüía que sus pruebas habían sido elaboradas fuera del Tratado de No Proliferación de Armas Nucleares (TNP), en respuesta a "la política hostil, chantajes y amenazas nucleares de Estados Unidos".

\section{PATRONES DE LA RELACIÓN CHINA - COREA DEL NORTE}

Ambos países se han caracterizado por tener una relación de codependencia, formando un binomio de influencia en la región, encabezado por China. En palabras de Mao Tse Tung la relación de tal proximidad que bajo su mandato llegaron a ser "tan cercanos como los labios y los dientes". Esto logró institucionalizarse significativamente a partir del Tratado de Amistad, Cooperación y Asistencia Mutua de 1961. Este "se ha renovado en dos ocasiones (1981 y 2001) y deberá de refrendarse en 2021. El eje del acuerdo es la cooperación militar: 
con la firma del documento cada parte ofreció defender a la otra en caso de un ataque externo, además de comprometerse a consultar al otro acerca de asuntos internacionales de interés común, brindarse toda la ayuda técnica y económica posible y consolidar sus lazos culturales y científicos"12.

La relación quedó contractualmente forjada a partir de aquel tratado de amistad, que refrendada el principio de defensa militar con el que Corea del Norte había consolidado su autonomía. Se configuró como un ritual de tal importancia, que el "Presidente chino Hu Jintao y el líder norcoreano Kim Jong-il declararon el 2009 como "Año de la Amistad" entre ambos países, en conmemoración del sexagésimo aniversario del establecimiento de relaciones diplomáticas"13.

China ha sido enlace importante de Corea del Norte con la comunidad internacional, y según Song y Lee el país ha ajustado sus prioridades dependiendo de las relaciones que mantiene con Estados Unidos y su percepción del estatus doméstico en el que la RPDC se ha encontrado, asi como el nivel de la relación que mantiene con la Corea comunista. Frente a esto, China ha articulado su política en relación a la RPDC a partir de dos variables: (1) la estabilidad de Corea del Norte; y (2) la probabilidad de intervención militar de los EE.UU.

China ha realizado una vinculación blanda con la RPDC, dando prioridad a la estabilización del régimen norcoreano, "cuando la probabilidad de una intervención militar estadounidense ha sido baja y Corea del Norte ha sido inestable"14.

Cuando la probabilidad de una intervención militar de EE.UU. ha sido alta y Corea del Norte se ha mantenido estable, China ha demostrado elegir una participación semi-dura "para evitar que Estados Unidos use su poder militar mientras presiona al Norte sobre la desnuclearización y para suavizar su reacción”15.

Tabla 1 Tendencia vinculación China - RPDC ${ }^{16}$

\begin{tabular}{|l|l|l|}
\hline Comportamiento de China & Estabilidad de la RPDC & $\begin{array}{l}\text { Probabilidad intervención } \\
\text { EE.UU. }\end{array}$ \\
\hline Vinculación blanda & Inestabilidad & Baja \\
\hline Vinculación semi-dura & Inestabilidad & Alta \\
\hline Vinculación dura & Estable & Baja \\
\hline
\end{tabular}

12 MÁRDERO, Gabriela. Camaradas Distantes: La Relación entre China y la República Popular Democrática de Corea en la Era del auge Nuclear Norcoreano. 2017. p. 846.

13 Ibíd. p. 847.

14 SONG, Wenzhi y LEE, Sangkeun. China's Engagement Patterns towards North Korea. Pacific Focus, Inha Journal of International Studies. 2016. p. 27.

15 Ibíd.

16 Basado en SONG, Wenzhi y LEE, Sangkeun. Loc. Cit. 
Finalmente, China ha elegido una vinculación o participación dura hacia Norcorea para ejercer presión por la desnuclearización "cuando la probabilidad de una intervención militar estadounidense ha sido baja y Corea del Norte se ha mantenido estable"17.

Estados Unidos "considera la cooperación de China como elemento esencial para una política exitosa hacia Corea del Norte"18. La percepción norteamericana, unida a la concepción de la comunidad internacional, han condicionado el comportamiento de China en relación a su aliado de la Guerra Fría. China ha tenido que lidiar con un balance entre la presión y cooperación con Corea del Norte. No obstante, la presión directa a Corea del Norte para que renuncie a su programa nuclear ha perjudicado la relación bilateral.

\section{Rusia como variable interviniente}

A la par con la relación entre China y Corea del Norte, Rusia siempre ha estado como potencial socio estratégico a punto de superar a Beijing en cercanía. China ha cimentado de alguna manera su comportamiento bajo la sombra de Rusia, especialmente desde el momento en que Kim Jong Un llegó al poder en 2011. El mandatario norcoreano "ha intentado fortalecer los lazos con Moscú para balancear sus dificultades con Beijing, el compromiso económico de Corea del Norte con Moscú se ha expandido, pero no mucho, aunque ambos países son sujeto de grandes sanciones de Occidente" 19 .

Incluso a nivel de planes bilaterales, tanto el gigante de Europa del Este como la RPDC han establecido lineamientos de consolidación de infraestructura y vinculación con el continente euroasiático. "Los representantes rusos y norcoreanos han discutido vincular un tren trans-coreano con el sistema de ferrocarriles de Rusia, el cual permitiría a este convertirse en un país de tránsito para el comercio de Corea del Sur con Europa, que ahora incluye principalmente envíos a larga distancia. Desafortunadamente para Moscú, la implementación de estos ambiciosos planes para construir vías del tren, tuberías y otros conductos a través de la península coreana permanecen frustrados por la adversa situación de seguridad de la región"20.

Así, Corea del Norte se ha ido identificando aún más con Rusia, especialmente a nivel del perfil fuerte e insurgente del liderazgo de ambos mandatarios. Por otra parte, China, bajo el alero de Xi Jin Ping, tiene un cimento de liderazgo colectivo amparado por la dinámica del centralismo democrático que estructura

lbíd.

18 Ibíd. p. 24.

19 WPR What's Driving Russia's Approach to Ties With North Korea? Friday August 18th. World Politics Review. 2017.

20 Ibíd. 
el Partido Comunista Chino. No obstante, el último Congreso del Partido Comunista forjó nuevos lineamientos que han ido desagregando el liderazgo colectivo que caracterizaba a la administración china. Xi Jin Ping ha articulado un carácter personalista como líder del PCCH y de la República Popular.

EI XIX Congreso reconfiguró la elite comunista, pero sin posicionar a alguien como eventual sucesor de Xi Jin Ping para dentro de cinco años, como se había realizado en otros congresos, como en el de 2008 con Hu Jintao al mando. A su vez, el Congreso llegó incluso a institucionalizar el pensamiento de Xi Jinping al incorporar la idea de "sueño chino" en constitución del partido junto a la filosofía de líderes históricos como Mao Zedong y Deng Xiaoping. Esto da pie a que Xi Jin Ping sea reelecto para un tercer mandato en 2022, generando un referente desde la muerte de Deng Xiao Ping.

\section{Cumbre EE.UU. - Corea del Norte: Variable interviniente}

La RPDC ha establecido distintas señales de muestras de buena fe. Esto, a través de la respuesta a petitorios antiguos provenientes de EE.UU., como lo fue la liberación a principios de mayo de tres ciudadanos estadounidenses, e incluso llegó a materializar el desbaratamiento del centro de pruebas nucleares ubicado en Punggye-ri.

Asimismo, el viaje de Kim a China, los líderes coreanos celebraron el viernes 27 de abril la histórica cumbre en la que se comprometieron a trabajar hacia una completa desnuclearización de la península.

El siguiente gran paso en el proceso fue la reunión entre Trump y Kim, la cual, a pesar de haber experimentado dificultades, siendo suspendida debido a tensiones entre autoridades norteamericanas y norcoreanas, finalmente se realizó en Singapur el 12 de junio. Esto marcó un hito diplomático de gran envergadura, que más allá de compromisos generales por parte de Corea del Norte, fue una movida significativa para realzar a Trump como el gran conciliador del siglo XXI, más allá del perfil de autoridad intransigente y volátil que ha demostrado ser en los primeros dos años de su mandato.

Por otra parte, el acercamiento hacia Estados Unidos es parte de un proceso gradual, del cual probablemente las sanciones económicas fueron un factor importante que colaboró con impulsar la apertura de Kim Jong Un bajo una dinámica de presión constante.

El papel de China en "Six Party Talks" (P6), también denominada Conversaciones de las Seis Partes ha sido fundamental. Estas consisten en negociaciones multilaterales realizadas entre China, Japón, Corea del Norte, Rusia, Corea del Sur y Estados Unidos con el fin de desmantelar el programa nuclear de Corea del Norte. No obstante, han tomado lugar intermitentemente desde 2003. Las conversaciones fueron organizadas en Beijing y presididas por China. En 2009 Corea del Norte decidió no seguir participando en el proceso. En años posterio- 
res, y especialmente en los últimos años, otros participantes como China, han pedido periódicamente que se reanude el proceso.

A partir de los acercamientos con el P6, China "crea un acto de equilibrio delicado para Beijing respecto a sus relaciones con la RPDC. Aunque la desnuclearización de la península coreana sería deseable para China, Beijing reconoce plenamente la situación de seguridad de Pyongyang y su percepción de que está completamente rodeada de potencias nucleares o países bajo el paraguas nuclear estadounidense y que Corea del Sur, Japón y Estados Unidos son poderes "hostiles"21. No obstante, si bien China reconoce la situación norcoreana, su estrategia de soft balancing a través de alianzas de distinto tipo, como lo ha sido el BRICS, hace que su acercamiento en relación a los poderes hegemónicos sea mucho menos directo y confrontacional que la actitud adoptada por la RPDC.

En este sentido, Chile a nivel regional ha cumplido un rol similar. Si bien el país del sur del mundo no aplica una lógica de soft balancing ya que no tiene una pretensión de revertir el orden hegemónico, sí ha ejercido un papel de país bisagra, lo cual ha conllevado que a nivel latinoamericano sea un actor clave en mediación de conflictos.

Su participación en Operaciones de Paz; su desempeño protagónico en el proceso de paz en Colombia, su calidad de "País Acompañante" en las conversaciones sostenidas entre el gobierno colombiano con las FARC (desde 2012) y su calidad de "País Garante" con el ELN (desde 2015); y su involucramiento en las iniciativas de resolver la crisis venezolana a través de distintas instancias como el Grupo de Lima, hacen de Chile un articulador de consenso a nivel regional.

Esto, sin lugar a dudas, es un background fundamental para insertarse al Asia Pacífico, y una manera estratégica de exportar una idea y sello de país que puede ser puente hacia otra región porque sin lugar a dudas cumple un rol bisagra a nivel intrarregional.

De esta manera, se pueden esbozar líneas que permiten identificar elementos que reflejen la importancia del vínculo de China con Corea del Norte y la integración de Chile en la región asiática. En esto la estabilidad interna de Chile es fundamental, ya que hacen de este un socio confiable.

De aquí se desprenden dos articuladores claves; por un lado, se encuentra China con su centralismo democrático y control unipartidista que requiere de actores que posean una estabilidad doméstica relativa gobernado por un régimen democrático, como lo es Chile. Por otro, se observa un país del cono sur bajo el alero del neoliberalismo, un cimento de Tratados de Libre Comercio que ha ceñido su integración con el mundo, y que ha consolidado legitimidad bajo la apertura económica, encontrando un enorme mercado en China, potencia en

21 NANTO, Dick K. y MANYIN, Mark. China-North Korea Relations. 2010 CRS Report for Congress. Congressional Research Service. p. 11. 
ascenso. Frente a esto, tanto China como Chile podrían explotar estos elementos en común, que resultan ser co-dependientes o al menos mutuamente complementarios, especialmente como focos de construcción de estabilidad en la región asiática y en la región latinoamericana respectivamente.

\section{Relación actual China - Corea del Norte}

El vínculo bilateral ha decaído desde que Kim Jon Un llegó al poder, especialmente en relación a la apertura que China ha sostenido a nivel económico y cómo esto podría incidir en la toma de decisiones en Corea del Norte, cuya economía se ha mantenido aislada del librecambismo y la economía de mercado.

Un ejemplo de la percepción de recelo y amenaza con la que el líder norcoreano veía desde sus inicios a China se refleja en la ejecución de Jang Songthaek, tío y asesor directo de Kim Jong Un, acusado de traición a la patria. Una de las razones de la ejecución se vincula con la cercanía de Jang Song-thaek a China y su apoyo a la reforma económica de Beijing, representando una amenaza al liderazgo de su sobrino y, por ende, al sistema de priorización militar de Norcorea.

Asimismo, en 2017 e inicios de 2018, mientras Corea del Norte lanzaba misiles de prueba, simultáneamente China celebraba eventos de alto perfil, lo cual ha simbolizado un desapego entre ambos países, especialmente desde la parte coreana.

Ejemplo de ello fue el discurso de Xi Jinping en la cumbre BRICS, poco después de la prueba del 3 de septiembre de 2017, ya que el mensaje que entregó solo hizo alusiones vagas a Corea del Norte, a pesar de ser un país en vías de desarrollo, elemento común que identificaría a Corea del Norte con el resto de los países del BRICS. La opinión pública internacional, a través de los medios de comunicación, enfatizó en cómo la situación reflejaba que el comportamiento de Corea del Norte era provocador, intentando restarle importancia a China y en particular a Xi Jin Ping como líder e influyente. Incluso, tal y como indicó Adam Cathcart, académico especialista en China, la bomba de Kim estaba "golpeando el podio de $\mathrm{Xi}^{\prime 22}$. Esto representó un malestar generalizado por parte de China, y en particular frente al personalismo que ha adoptado Xi Jin Ping, ad portas del XIX Congreso del Partido Comunista de China, realizado en noviembre de 2017.

Tras dos décadas de relaciones decrecientes entre Corea del Norte y China, Kim Jong Un se reunió a fines de marzo con Xi Jin Ping en Beijing, realizando por primera vez una visita oficial desde que asumió el poder. "Solo seis intercambios bilaterales de alto nivel habían tenido lugar en los últimos seis años, en

22 CATHCART, Adam. The timing of North Korea's nuke test could not be worse for China's leader. The Washington Post. [En línea] 2017. [Consulta: 4 junio 2018]. 
comparación con 54 durante la presidencia de su predecesor, Hu. Jintao"23. En esa oportunidad, Kim afirmó que el tema de desnuclearización de la península coreana se resolvería si Corea del Sur y EE.UU. respondiesen a sus esfuerzos con buena voluntad.

El contraste de la reunión también se vio reflejado en cómo el mandatario coreano felicitó a Xi Jin Ping por su segundo mandato de cinco años tras el XIX Congreso del Partido, ya que en el primer nombramiento de Xi Jin Ping en 2013 Kim Jong Un entregó un mensaje de cercanía, enfatizando conceptos como "fuerza del liderazgo mutuo, amistad y hermandad"24, apelando a la situación de compañerismo y fraternidad que mantenían, versus a una relación más fría y lejana, que es la que sostienen actualmente.

China ha prohibido a los prestamistas nacionales hacer negocios con clientes norcoreanos además de detener ciertas exportaciones en cumplimiento de las sanciones internacionales. No obstante, cifras recientes mostraron un aumento anual de $3.7 \%$ en el comercio bilateral durante los primeros nueve meses del año ${ }^{25}$.

Pese a las serias restricciones, se ha observado en los últimos años la proliferación de un activo mercado negro, con bienes provenientes de Corea del Sur y China. Pese a los controles establecidos por Corea del Norte, el incremento del contrabando podría convertirse en una amenaza no menor al rígido sistema de planificación económica

El cuadro de más abajo explica cómo ambos países difieren de un sistema político y económico, ya que los dos liderazgos recienten la falta de apego a la interpretación.

23 SKYLAR, Oriana. What China Gained From Hosting Kim Jong Un. 2018. Foreign Affairs.

24 CHANDRAN, Nyshka. North Korea's relationship with its sole ally is losing steam. Entrevista a Kim Tae-hyo, political science professor at Seoul-based Sungkyunkwan University. 2017.

25 Ibíd. 


\section{Distanciamiento según percepción}

\begin{tabular}{|c|c|c|}
\hline Criterio & Razones de distanciamiento de China & $\begin{array}{l}\text { Razones de distanciamiento de } \\
\text { Norcorea }\end{array}$ \\
\hline Seguridad & $\begin{array}{l}\text { China percibe cada vez más que el pro- } \\
\text { grama nuclear norcoreano está dañando } \\
\text { la seguridad asiática }{ }^{26} \text {. }\end{array}$ & $\begin{array}{l}\text { Para Norcorea, China no comparte la } \\
\text { misma visión y estrategia de posicio- } \\
\text { namiento en el contexto internacio- } \\
\text { nal. China concuerda con la política } \\
\text { norcoreana de priorizar lo militar a } \\
\text { través de su desarrollo como Estado } \\
\text { nuclear. }\end{array}$ \\
\hline Político & $\begin{array}{l}\text { El sistema de liderazgo feudal sostenido } \\
\text { por Corea del Norte se contrapone al sis- } \\
\text { tema de centralismo democrático chino, } \\
\text { matriz decisional fundamental que China } \\
\text { sigue implementando }{ }^{27} \text {. }\end{array}$ & $\begin{array}{l}\text { Perfil del liderazgo: Kim Jong II per- } \\
\text { cibía cercanía con China, especial- } \\
\text { mente con Hu Jintao. Kim Jong Un ve } \\
\text { con recelo la injerencia de China en } \\
\text { los asuntos norcoreanos. } \\
\text { Resabios históricos en los que Co- } \\
\text { rea del Norte mantenía originalmente } \\
\text { mayor cercanía con la URSS, ya que } \\
\text { en esencia la RPDC era un satéli- } \\
\text { te soviético, no chino a inicios de la } \\
\text { Guerra Fría. } \\
\text { Percepción de desconfianza en el } \\
\text { imaginario colectivo de los lideres } \\
\text { norcoreanos: "La guerra chino-viet- } \\
\text { namita dejó una profunda impresión } \\
\text { en los vecinos inmediatos de China } \\
\text { en Asia y su principal lección debe } \\
\text { haber sido obvia para Corea del Nor- } \\
\text { te: China no dudaría en abandonar a } \\
\text { un aliado o en el aislamiento del uso } \\
\text { de la fuerza para promover sus inte- } \\
\text { reses nacionales"28. }\end{array}$ \\
\hline
\end{tabular}

26 XIAOHE, Cheng. China in the World Podcast. Episode 94: Will China Change its Approach to North Korea? September 27, 2017. Carnegie-Tsinghua, Center for Global Policy.

27 Ibíd.

28 GADY, Franz-Stefan. War of the Dragons: Why North Korea Does Not Trust China. The legacy of the SinoVietnamese War continues to cast a shadow on China-North Korea relations. The Diplomat, september 2017. 


\begin{tabular}{|c|c|c|}
\hline Criterio & Razones de distanciamiento de China & \begin{tabular}{|l|} 
Razones de distanciamiento de \\
Norcorea \\
\end{tabular} \\
\hline Económico & $\begin{array}{l}\text { Necesidad de ser portavoz de la preocu- } \\
\text { pación de la comunidad internacional y } \\
\text { legitimar el sistema multilateral al acatar } \\
\text { y sumarse a las sanciones económicas } \\
\text { establecidas por Resoluciones de Nacio- } \\
\text { nes Unidas: } \\
\text { - RES } 2397 \text { (septiembre 2017) Refuerza } \\
\text { las medidas relativas al suministro, venta } \\
\text { o transferencia a la RPDC de productos } \\
\text { petrolíferos refinados. } \\
\text { - Res } 2375 \text { (septiembre 2017) Prohibi- } \\
\text { ción total del suministro, venta o transfe- } \\
\text { rencia de todos los condensados y líqui- } \\
\text { dos de gas natural a la RPDC. } \\
\text { - RES } 2371 \text { (agosto 2017) Prohibe im- } \\
\text { portar carbón, hierro y mineral de hierro, } \\
\text { plomo y mineral de plomo a los produc- } \\
\text { tos prohibidos sujetos a sanciones sec- } \\
\text { toriales. } \\
\text { - RES } 2094 \text { (marzo 2013) Impone san- } \\
\text { ciones financieras específicas; amplía la } \\
\text { lista de artículos nucleares prohibidos, } \\
\text { misiles balísticos y otros artículos rela- } \\
\text { cionados con armas de destrucción ma- } \\
\text { siva. } \\
\text { - RES } 1874 \text { (junio 2009) Insta a los Es- } \\
\text { tados Miembros a que impidan la presta- } \\
\text { ción de servicios financieros o la trans- } \\
\text { ferencia de recursos financieros que } \\
\text { podrían contribuir a programas/ activida- } \\
\text { des prohibidos. }\end{array}$ & $\begin{array}{l}\text { El estilo de gobierno de Kim Jong Un } \\
\text { es distinto al de su padre y antecesor, } \\
\text { el cual estaba interesado en estable- } \\
\text { cer concesiones económicas median- } \\
\text { te negociaciones internacionales y } \\
\text { sin amenazar nuclearmente a EE.UU. } \\
\text { Kim Jong Un era menos propenso en } \\
\text { realizar conversaciones diplomáticas, } \\
\text { lo cual se evidenciaba especialmente } \\
\text { con China }{ }^{29} \text {. }\end{array}$ \\
\hline
\end{tabular}

Fuente: Elaboración propia.

En materia de seguridad, de la tabla de más arriba se logra destacar que China utiliza y reconstruye su poder militar bajo un imaginario de no abuso distinto a un uso discursivo más directo por parte de Corea del Norte.

A nivel de estilo político, la idea de autonomía e independencia que China profesa a nivel extra-regional continúa siendo un elemento de tensión en el plano regional. Esto se ve reflejado en la reticencia de Kim Jong Un en retomar la percepción de amistad o de aliado sostenida por su antecesor y dejar de observar con desconfianza el potencial de influencia de China en asuntos domésticos.

29 Ibíd. 
Por otra parte, y como una forma de persuasión material, el factor económico ha sido un reflejo de la construcción de vínculos discursivos que había articulado el antecesor del actual gobernante norcoreano. Esto se manifiesta en la identificación de China como amigo y socio en tiempos anteriores a la injerencia de Consejo de Seguridad a raíz de las pruebas nucleares en la península asiática.

Además de las resoluciones respecto a la amenaza nuclear en el seno de Naciones Unidas, China ha tenido una participación más activa y reaccionaria en torno a la RPDC en otros espacios multilaterales. Esto se ha visto reflejado en instancias como el Consejo de Derechos Humanos (CDH), donde ambos países pueden ser interpelados al tomar en consideración la naturaleza autocrática de ambos regímenes, los cuales han obtenido el estatus de "No libre" según los indicadores entregados por Freedom House ${ }^{30}$. En este sentido, en materia de derechos políticos, libertad de prensa y libertades civiles, ambos países tienen los índices de menor libertad a nivel mundial. Si bien la potencia asiática detenta mayores libertades civiles ${ }^{31}$, su puntuación no es considerablemente mejor en comparación con el régimen cerrado de Corea del Norte ${ }^{32}$.

En el CDH, "China bloquea iniciativas que buscan responsabilizar al gobierno norcoreano por violaciones de los derechos humanos de su población y se rehúsa también a asumir posturas enérgicas contra ese país, como cuando se documentó de manera suficiente que la RDPC estuvo detrás del hundimiento de un barco militar surcoreano en 2010, el cual dejó casi cincuenta marinos muertos. En general, China se conduce hacia Corea del Norte en el ámbito multilateral con una marcada ambivalencia, lo cual, sumado a la poca interacción -al menos oficial- entre sus élites políticas y partidistas, dificulta arribar a conclusiones claras sobre el estado de la relación bilateral" ${ }^{\prime 3}$.

Tras una concatenación de eventos que han distanciado al gigante asiático respecto a Corea del Norte, el liderazgo por la pacificación de la península coreana ha recaído en Estados Unidos. Ello se ve reflejado en la coordinación de la Cumbre por parte de la potencia norteamericana, sostenida en junio de este año y las tensiones previas manifestadas para que esta instancia histórica se llevase a cabo. Frente a esto, China se ha desenmarcado de la tensión latente que presenta la amenaza norcoreana, dejando de posicionarse como un aliado sine qua non, para comenzar a identificarse como otro actor que de alguna manera

30 FREEDOM HOUSE. China Country Report 2018 [En línea]. 2018. [Consulta: 5 marzo 2018].

31 China obtuvo una puntuación de 6/7 de 7/7 en una escala en que 1 es Más libre y 7 es Menos libre, mientras bajo el mismo indicador la RPDC obtuvo 7/7, siendo el menos libre.

32 FREEDOM HOUSE. North Korea Country Report 2018 [En línea]. 2018. [Consulta: 5 marzo 2018].

3з MÁRDERO, Gabriela. Op. Cit. p. 863. 
contribuyó a que la RPDC, y en particular su líder, llegara a generar un llamado de atención internacional con gran peso disuasivo.

Asimismo, en la instancia mencionada, "Kim Jong-un declaró que la amistad entre la Pyongyang y Beijing es un legado dejado por las generaciones mayores de líderes de los dos países y es valioso y preciado. Consolidar y desarrollar la cooperación amistosa entre la RPDC y China es una política estratégica inquebrantable de la primera" 34 .

La visita que realizó Kim Jong Un a China y el primer encuentro en 11 años realizado entre el canciller chino, Wang Yi, a Pyongyang demuestran el interés de las autoridades chinas en recomponer la relación y dar una señal a que está cumpliendo un rol de enmarcar la solución del diálogo por la pacificación de la península.

La potencia asiática ha estado como figura latente en todo el proceso de conversaciones hacia el comienzo de desnuclearización de la península coreana. Xi Jinping ha explicitado la opción de otorgar asistencia económica a la RPDC bajo la condición de que llegase a un acuerdo con EE.UU. De esta manera, Beijing no abandona su capacidad de incidir en la toma de decisiones de Corea del Norte, a pesar de que gran parte del mérito de haber llegado a la posibilidad de establecer encuentros, como el realizado el 12 de junio en Singapur, corresponde a la capacidad de reflexionar y flexibilizar su postura por parte de Corea del Norte.

La decisión china de asistir económicamente a Pyongyang marca una diferencia respecto a cómo hace 8 años atrás, en la última visita que realizó Kim Jong-il a China, Xi Jinpin decidió no incluir una recompensa económica para intentar de persuadir o modificar el comportamiento de Corea del Norte. Los últimos acontecimientos han reflejado una distensión entre la constante y compleja política que ha tenido que adoptar China respecto a la península norcoreana. "Las crecientes tensiones entre los intereses compartidos de Pekín con Pyongyang y sus crecientes diferencias con ese gobierno han creado una imagen compleja y turbia para los tomadores de decisión estadounidenses que han tratado de convencer a Pekín de ser más coercitivo con Pyongyang y más cooperativo con Washington en su intento de cerrar el programa de armas nucleares" ${ }^{\prime 3}$. No obstante, esto es un elemento que se ha modificado bajo los últimos acontecimientos en el seno de la serie de cumbres de diálogo que se han realizado este año, favoreciendo la imagen de Estados Unidos como actor dispuesto a consensuar y China como un articulador pasivo y reactivo.

Sin lugar a dudas, Estados Unidos, y en particular Donald Trump, pasarán a la historia con este episodio clave dentro de las relaciones de no tan solo Corea

$34 \quad$ FMPRC (DPRK Top Leader Kim Jong-un Meets with Wang Yi [En línea] 3 de mayo 2018 [Consulta: 10 mayo 2018].

$35 \quad$ NANTO, Dick K. y MANYIN, Mark. Loc. Cit. 
del Norte con su país, sino que también a nivel regional, siendo parte importante del acercamiento de las dos Coreas, lo cual lo posiciona en un podio en la construcción de una identidad hegemónica para la región asiática.

\section{COREA DEL SUR COMO VARIABLE INTERVINIENTE}

\section{China y Corea del Sur}

Desde fines de marzo 2018, las relaciones se han ido intensificando, especialmente en el contexto de los preparativos para las cumbres de Corea del Norte con Corea del Sur y EE.UU. En este marco, Kim Jong Un visitó China a inicios de mayo para sostener la segunda reunión con Xi Jin Ping en menos de 6 semanas.

La visita fue simbólica, y además fue complementada con la primera cumbre trilateral entre China, Corea del Sur y Japón, ya que el Primer Ministro Li Keqiang, de China, el presidente Moon Jae-in de Corea del Sur y el Primer Ministro Shinzo Abe de Japón para abordar la desnuclearización de la península coreana, así como los resultados de la Cumbre Intercoreana realizada en abril.

Por otra parte, según Song y $\mathrm{Lee}^{36}$, la relación entre la RPDC y China se ha deteriorado rápidamente desde que este último país estableció relaciones diplomáticas con Corea del Sur en 1992. Esto se vio reflejado entre 1991 y el año 2000 , periodo en el cual las visitas oficiales de los altos mandatarios fueron suspendidas.

\section{Las dos Coreas}

La realización de Cumbres intercoreanas ha sido un elemento fundamental para la estabilidad regional, teniendo incluso una incidencia en la estabilidad doméstica de Corea del Norte, el cual se estabilizo rápidamente en la Cumbre Intercoreana realizada en junio del año 2000. De esta manera, cuando Corea del Norte mejoró exitosamente su relación con Corea del Sur, fue capaz de obtener recursos necesarios para superar las dificultades financieras, debido a la interrupción en las relaciones económico-comerciales de ambos países.

Uno de los hitos de los últimos años ha sido el acercamiento entre ambas Coreas, manifestado en la cumbre realizada en abril y la reciente reunión sostenida sin previo aviso mediático a finales de mayo. Esto refleja cómo Corea del Sur se va posicionando como un aliado regional importante, desplazando a China dentro de la escena de socios y complicidad bajo la opinión pública internacional.

La situación en la península coreana se ha encaminado hacia la paz y reconciliación a partir de la cumbre entre Corea del Norte y del Sur a fines de abril, y la Declaración de Panmunjom que emanó de la cumbre.

36 SONG, Wenzhi y LEE, Sangkeun. Op. Cit. p. 9. 
Corea del Norte anunció en su momento la reapertura de la planta nuclear de Yongbyon, cerrada en 2007, en el marco de las fallidas negociaciones de entonces, haciendo de esto un patrón indicativo de su intento de utilizar la escalada nuclear con el objetivo de obtener un piso de apoyo para retornar a las negociaciones y tener una moneda de cambio.

Norcorea incluso anunció el desmantelamiento del terreno de pruebas de Punggye-ri, localizado en el noreste de la RDPC, lo que se concretó a fines de mayo del año en curso.

\section{CHILE Y SU RELACIÓN CON CHINA Y COREA DEL NORTE}

Chile y Corea del Norte no tienen misión de representación o embajadas residentes, por lo que las relaciones bilaterales son atendidas desde la embajada del país del hemisferio sur en la República Popular China y por la Embajada de la República Popular Democrática de Corea en Brasil. Desde 2016, las relaciones con Corea del Norte han sido atendidas desde la embajada de Chile en la República de Corea.

Santiago condena el ejercicio de pruebas nucleares por parte de Pyongyang, y ha aprobado todas las resoluciones de Naciones Unidas que condenan y establecen sanciones al régimen de la RPDC. Asimismo, el país latinoamericano ha expresado al Organismo Internacional de Energía Atómica (OIEA) su apoyo a la labor que realiza en relación al programa nuclear de la RPDC. Esto cobra especial relevancia en torno a este como país de desarrollo nuclear medio. Santiago, "habiendo firmado el TNP, no domina el ciclo del combustible y por lo tanto, carece de autonomía en esta materia, tampoco Chile cuenta con una política nuclear como política de Estado, su desarrollo nuclear es mediano, los reactores son sólo de investigación"37.

Frente a esto, el país del cono sur comparte el diagnóstico de que es necesario que la RPDC se reincorpore al Tratado de No Proliferación Nuclear (TNP) y permita la implementación de salvaguardias en sus instalaciones, renunciando completamente a los usos no pacíficos de la energía nuclear. Para el país latinoamericano, el Desarme y la No Proliferación de las Armas Nucleares es uno de los ejes principales de su política exterior en materia de seguridad internacional, $\mathrm{y}$ ha apoyado a las instancias multilaterales que trabajan en ello.

37 CUBILLOS MEZA, Adela. El Tratado de no Proliferación Nuclear: la vigencia de la norma en América Latina. Revista Universum Nº 20 Vol. 1: 12-20, 2005. 


\section{CONCLUSIONES}

La relación de codependencia entre la Corea Comunista y el gigante asiático ha estado articulada por el factor interviniente de Estados Unidos y la estabilidad doméstica de la RPDC. Frente a esto, China ha tenido que lidiar con un balance entre la presión y cooperación con Corea del Norte, manteniendo la construcción de un discurso de fraternidad con su par, pero con matices propios de una potencia en ascenso que debe adaptarse al discurso universal de una comunidad internacional pro democrática y apegada a las normas del derecho internacional y el pacifismo.

En relación a las tensiones regionales, si bien tanto la RPDC como China se han alejado en términos del binomio de valores, principios y lineamientos de política exterior compartidos, China será imprescindible para lograr establecer garantías de seguridad en el proceso de diálogo que se está consolidando.

Respecto a Corea del Norte y el proceso de desnuclearización de la península coreana, la supresión de sanciones económicas y la entrega de compensaciones han sido beneficios que la RPDC ha intentado proteger a toda costa por la estabilidad doméstica, siendo fundamental en su disposición por mantener el diálogo. El caso de Libia y su proceso de desnuclearización de los años 20032004 ha sido un elemento clave para que Kim Jong Un reconsidere los términos de un acuerdo de desnuclearización total. Es por esto que el Memorándum de Budapest y lo sucedido con Muamar Al Kadafi son un referente disuasivo y de incertidumbre que enfrentaría a Corea del Norte en el proceso. Sin embargo, el factor que diferencia el caso norcoreano con el de Libia es China y su capacidad de amortiguar los efectos de su toma de decisión volátil y los efectos colaterales que puedan surgir desde la comunidad internacional, y en particular desde Estados Unidos.

Si bien la comunidad internacional observa con escepticismo los últimos intentos y señales de diálogo y reconciliación que ha establecido Corea del Norte en relación a Corea del Sur y Estados Unidos, se debe atender más de cerca la construcción de identidad que la RPDC ha creado a lo largo de los años, suficientemente alejada de EE.UU. y de Corea del Sur. La identidad de un país autónomo y aislado sigue vigente, solo que, bajo el diálogo y demostración de voluntad por obtener consenso, pierde su visibilidad.

\section{Chile y su rol como actor bisagra}

Para Chile es vital integrarse a Asia bajo el mismo paraguas reconciliador con el que ha lidiado a nivel regional. El rol que ha cumplido con países y la pacificación en conflictos armados como el de Colombia hacen de Chile un Estado capaz de integrarse a la región asiática. 
Mientras tanto, instancias y proyectos de sello chino como "One belt, One road" (OBOR) también deben ser parte articuladora para que Chile pueda consolidarse en su papel de puente al Asia Pacífico. Esto cobra especial relevancia si se considera que Corea del Sur propone un modelo de integración dirigido a unir Eurasia, mientras los ejes de OBOR sientan el camino hacia la infraestructura e interconectividad con Chile.

Los acuerdos, tratados de libre comercio, cooperación, institucionalización de alianzas público-privadas y la consolidación de start ups son ejes que van a configurar una estrategia de inserción cada vez más sólida. Todo esto para que Chile logre superar su susceptibilidad a la interdependencia compleja, que de alguna manera lo expone al poseer una matriz productiva poco diversificada. De esta manera podremos llegar al punto en estar preparados, así como los desastres naturales han forzado a crear estrategias de resiliencia para prevenirlos y enfrentarlos.

Sin lugar a dudas el rol de Chile como país bisagra hacia la resolución de conflictos, la estabilidad política y la apertura comercial, impronta que lo caracteriza en su comportamiento histórico, especialmente a nivel regional, es un factor que tanto los países de Asia como del resto del orbe han notado pero que debe ser potenciado para así articular el tejido de un puente concreto hacia el otro rincón del mundo. 


\section{REFERENCIAS BIBLIOGRÁFICAS}

ACHARYA, Alka. "India-China Relations: Towards a 'Shared Vision". Economic and Political Weekly. Vol. 43, No. 4 (Jan. 26 - Feb. 1, 2008) pp. 10-13.

ADLER, Emanuel. Seizing the Middle Ground: Constructivism in World Politics. European Journal of International Relations. 1997.

BARBÉ, Esther. Relaciones Internacionales. Editorial Tecnos (Grupo Anaya S.A.), Madrid. 2007.

BBC. Pompeo in North Korea ahead of Trump-Kim talks. [En línea] 2018. [Consulta: 10 de mayo 2018]. Disponible en: https://www.bbc.com/news/ world-us-canada-44048340

CATHCART, Adam. The timing of North Korea's nuke test could not be worse for China's leader. The Washington Post. [En linea] 2017. [Consulta: 4 junio 2018] Disponible en: https://www.washingtonpost.com/world/ the-timing-of-north-koreas-nuke-test-could-not-be-worse-for-chinasxi/2017/09/04/f9d0677a-90bb-11e7-b9bc-b2f7903bab0d_story. $\mathrm{html}$ ?noredirect=on\&utm_term=.6d98a077ccee

CHANDRAN, Nyshka. North Korea's relationship with its sole ally is losing steam. Entrevista a Kim Tae-hyo, political science professor at Seoulbased Sungkyunkwan University. 2017. Disponible en: https://www.cnbc. com/2017/10/27/china-north-korea-relationship-on-the-decline.html

COX, Robert. Social Forces, States and World Orders: Beyond International Relations Theory, Millenniuym Journal of International Studies. Vol. 10, No 2, 126-155. 1981. Disponible en: https://www.uni-erfurt.de/fileadmin/ public-docs/Internationale_Beziehungen/cox.pdf

COLACRAI, Miryam y LORENZINI, María Elena. La política exterior de Chile: ¿excepcionalidad o continuidad? Una lectura combinada de "fuerzas profundas" y tendencias. CONfines relacion. internaci. ciencia política [online]. 2005, vol.1, n.2, pp. 45-63. ISSN 1870-3569.

CUBILLOS MEZA, Adela. El Tratado de no Proliferación Nuclear: la vigencia de la norma en América Latina. Revista Universum No 20 Vol. 1: 12-20, 2005. Disponible en: https://scielo.conicyt.cl/scielo.php?script=sci_arttext\&pid $=$ S0718-23762005000100002

FMPRC Política exterior de paz bajo el principio de independencia y autodecisión de China. Ministerio de Relaciones Exteriores de la República Popular China. [En linea] 24 de agosto 2003 [Consulta:10 Febrero 2018]. Disponible en: http://www.fmprc.gov.cn/esp/wjdt/wjzc/t25297.htm 
FMPRC (DPRK Top Leader Kim Jong-un Meets with Wang Yi [En linea] 3 de mayo 2018 [Consulta: 10 mayo 2018]. Disponible en: http://www.fmprc.gov.cn/ mfa_eng/zxxx_662805/t1557115.shtml

FREEDOM HOUSE. China Country Report 2018 [En linea]. 2018. [Consulta: 5 marzo 2018]. Disponible en: https://freedomhouse.org/report/freedomworld/2018/china

FREEDOM HOUSE. North Korea Country Report 2018[En linea]. 2018. [Consulta: 5 marzo 2018]. Disponible en: https://freedomhouse.org/report/freedomworld/2018/north-korea

GADY, Franz-Stefan. War of the Dragons: Why North Korea Does Not Trust China. The legacy of the Sino-Vietnamese War continues to cast a shadow on China-North Korea relations. The Diplomat, september 2017. Disponible en: https://thediplomat.com/2017/09/war-of-the-dragons-why-north-koreadoes-not-trust-china/

KEOHANE, Robert. Relaciones Internacionales: Lo viejo y lo Nuevo. Nuevo Manual de Ciencia Política Editorial Istmo, España. 2001.

LEVI, Nicolas. The Importance of Confucian values to Kim Jong II's System: A comparison with Kim II Sung's Syste. 2012. Poland Asia Research Center.

MÁRDERO, Gabriela. Camaradas Distantes: La Relación entre China y la República Popular Democrática de Corea en la Era del auge Nuclear Norcoreano. 2017.

NANTO, Dick K. y MANYIN, Mark. China-North Korea Relations. 2010. CRS Report for Congress. Congressional Research Service.

PAPE, Robert. "Soft Balancing against the United States". Triangle Institute on Security Studies at Duke University. 2003.

SKYLAR, Oriana. What China Gained From Hosting Kim Jong Un. 2018. Foreign Affairs.

SONG, Wenzhi y LEE, Sangkeun. China's Engagement Patterns towards North Korea. Pacific Focus, Inha Journal of International Studies. 2016.

XIAOHE, Cheng. China in the World Podcast. Episode 94: Will China Change its Approach to North Korea? September 27, 2017. Carnegie-Tsinghua, Center for Global Policy. Disponible en: https://carnegieendowment.org/ files/Will_China_Change_its_Approach_to_North_Korea.pdf

WPR What's Driving Russia's Approach to Ties With North Korea? Friday August 18th. World Politics Review. 2017. 